\title{
HHV6 Infection
}

National Cancer Institute

\section{Source}

National Cancer Institute. HHV6 Infection. NCI Thesaurus. Code C128829.

An infection that is caused by human herpesvirus- 6 . 